\title{
Core attributes of stewardship; foundation of sound health system
}

\author{
Neelesh Kapoor ${ }^{1}$, Dewesh Kumar ${ }^{2, *}$, Nivedita Thakur $^{3}$
}

\section{Abstract}

Stewardship is not a new concept for public policy, but has not been used to its optimum by the health policymakers. Although it is being practiced in most successful models of health system, but the onus to this function is still due till date. Lately, few experts in World Health Organization (WHO) have realized its importance and have been raising the issue at different platforms to pursue the most important function of the health system i.e. stewardship. The core attributes of stewardship need to be understood in totality for better understanding of the concept. These core attributes, required for hassle free functioning of a health system, include responsible manager, political will, normative dimension, balanced interventionist and proponents of good governance.

Keywords: Stewardship, Health System, Governance, Manager

Copyright: @ 2014 by Kerman University of Medical Sciences

Citation: Kapoor N, Kumar D, Nivedita Thakur N. Core attributes of stewardship; foundation of sound health system. Int J Health Policy Manag 2014; 3: 5-6. doi: 10.15171/ijhpm.2014.52
Article History:

Received: 25 March 2014

Accepted: 21 May 2014

ePublished: 23 May 2014

${ }^{\star}$ Correspondence to:

Dewesh Kumar

Email: dr.dewesh@gmail.com

\section{Background}

In its world health report of 2000 (1) Health Systems: Improving Performance, World Health Organization (WHO) has identified stewardship as one of the four essential functions of health system beside service provision, resource generation and financing, so as to fulfill the three basic objectives of any health system, viz, improvement of health of population they serve, responding to people's expectations and providing financial protection against the costs of ill health. The report took a broad view of health systems as including: "The report took a broad view of health systems which include organizations, institutions and resources that are primarily involved in producing health actions. The primary purpose of health action is to improve health with the efforts in personal healthcare, public health services and through inter-sectoral initiatives" [WHR 2000, p. xi]. The report went on to argue that stewardship was the most important function and without it the synthesis and practice of the other three functions would be a futile exercise. Reemphasizing its importance, the task force on health systems research identified it as one of the key areas where research is required for the attainment of Millennium Development Goals (2). With a vision to bring further clarity to the concept of stewardship, Travis et al. even elaborated the domains or sub-functions of stewardship (3). But despite the wealth of debates and scientific research, little clarity exists about the pillars on which the function stands and can be nurtured. This paper thus tries to build upon the existing evidence and identify those core attributes which can throw light not only on the conceptual intricacies of stewardship but can also help researches identify new functional domains relevant to the state's stewardship role and eventually solve problems related to practical application of this concept.

\section{Definition}

Stewardship has been defined in different ways by different authors. One of the basic definition of stewardship describes it as "the disinterested performance of a duty by government and/or its agents on behalf of a superior" (4). During his extensive work on public administration, Kass described stewardship in relation with agency theory and defined it as "the administrator's willingness and ability to earn public trust by being an effective and ethical agent in carrying out the republic's business" (5). Block in his work on stewardship found it to be a set of principles and practices that have the potential to make dramatic changes in the governance of institutions. "Stewardship begins with the willingness to be accountable for some larger body than ourselves-a team, an organization, a community. It springs from a set of beliefs about reforming organizations that affirm our choice for service over the pursuit of self-interest" (6). Saltman in his seminal work has defined it as "function of a government responsible for the welfare of the population, and concerned about the trust and legitimacy with which its activities are viewed by the citizenry" (7). The world health report (2000) broadly defined stewardship as "the careful and responsible management of the well-being of the population", and in the most general terms as "the very essence of good government".

\section{Core attributes}

Responsible manager

The state has the overall responsibility of health of the population. The concept of health stewardship implies a broader over-arching responsibility over the functioning of the health system as a whole and ultimately, over the health of the population. It should nurture itself at all levels of healthcare so that there is co-ordinated involvement of all departments and sectors (8). The realization of this belief has to come from within and until it is there, the state will not be in a position to create an enabling environment and institutional arrangements in which all actors and stakeholders can perform their functions with utmost regard for the need to have optimum results to achieve the overall public good. Some researches even go on to argue that state has a duty to look after the health of every one and if required it also means guiding or restricting people's choices (9). Since the health of the people is a national priority, the government responsibility for it is continuous and permanent. 


\section{Political will}

As Saltman argues that while stewardship is potentially a model of governance which can infuse state policy-making and regulatory functions with an explicitly normative dimension, it requires clear and consistent strategic direction and the states themselves have to generate this, if stewardship is to provide a successful model of health policy-making, leading us to a question as to what will lead to such synthesis of self-realization and the only answer to it is political will. The state by itself is nothing but a mere actor unless it has the will to pull all sops to cut strings and behave in an authoritarian way to achieve what it ought to achieve. Nafees et al. argue that the concept of stewardship calls for a strong role of state in healthcare therefore a greater political will is inherent in it (10). The art and craft of being a responsible manager will come to a naught if there is no underlying will to succeed against all odds and behave as a steward rather than just believing in stewardship as a guiding principle.

\section{Normative dimension}

Earlier it has been emphasized that stewardship is a model which "incorporates concerns about efficiency into a more socially responsible, normative framework reinvigorating the broader social contract on which the state is based". In broader terms it is the state which is responsible to dissolve all inequalities with respect to health in different population groups. The reasons for them may be multifold, but it should not be because of injustice which though difficult to determine can be resolved only by adopting a normative approach based on content-oriented-values in the pursuit of policy-making that is both ethical and efficient.

\section{Balanced interventionist}

Ethnoven and Kronick believed stewardship to be an explicitly ethically based, outcome-oriented policy approach, which in contrast to the economically driven agency approach to the state regulation was substantially more interventionist. For them, stewardship held out the possibility of an activist state that designs the rules of competition in a socially accountable manner (11). The social accountability ensured that all interventions which would be thus made will balance out economic pulls and pushes which in themselves are a product of competing priorities and conflict of interests among not only the various stakeholders involved but also the other divisions of government which were not directly responsible for health of the people.

\section{Proponents of good governance}

Many researchers believe that stewardship and governance are synonymous and can be used interchangeably (12), while some other argue that the general thrust of good governance and stewardship is similar and although there is a need for them to be expanded conceptually they should be considered together (13). The idea although may be applicable in certain settings does not reflect the true scenario championed by WHO through its WHR 2000. Kaufman et al. have described governance as the "traditions and institutions by which authority in a country is exercised" (14). While governance more closely deals with the management arrangements of increasingly complex health systems, the stewardship forms the bedrock of underlying values and principles which in itself will guide those arrangements. In other words, if governance is body, stewardship is its soul.

\section{Conclusion}

The present paper tries to revisit the concept of stewardship with an aim to identify its certain core attributes, a better understanding of which will lead to identify strategies to nurture the stewardship function for those who are responsible for it. The suggested five attributes, viz, responsible manager, political will, normative dimension, balanced interventionist and proponent of good governance provide important clues to unique features of the stewardship concept and provide an insight to the researchers for advocating the cause of stewardship function with a focus on policy and practice.

\section{Ethical issues}

Not applicable.

\section{Competing interests}

The authors declare that they have no competing interests.

\section{Authors' contributions}

NK defined the concept and intellectual content of the paper; DK performed the literature search and drafted the manuscript; NT contributed to the design, review, and final editing of the manuscript.

\section{Authors' affiliations}

${ }^{1}$ Sub Regional Team Leader (NPSP-WHO), II Floor, Maternity Home, Peli Colony, Aishbagh, Lucknow (Uttar Pradesh), India. ${ }^{2}$ Department of Community Medicine and Family Medicine, All India Institute of Medical Sciences, Basni-II, Jodhpur (Rajasthan), India. ${ }^{3}$ Apollo Hospital, Sector-26, Noida (Uttar Pradesh), India.

\section{References}

1. World Health Organization (WHO). Health Systems: Improving Performance. The World Health Report. Geneva: WHO; 2000.

2. Task force on Health Systems Research. Informed choices for attaining the Millennium Development Goals: towards an international cooperative agenda for health-systems research. Lancet 2004; 364: 997-1003. doi: 10.1016/s0140-6736(04)17026-8

3. Travis P, Egger D, Davies P, Mechbal A. Towards better stewardship: Concepts and critical issues. In: Murray CJL, Evans DB, editors. Health systems performance assessment: Debates, methods and empiricism. Geneva: World Health Organization; 2003.

4. Shafriz JM. International encyclopaedia of public policy and administration Boulder: Westview Press; 1998.

5. Kass HD. Stewardship as a fundamental element in images of public administration. In: Kass HD, Catron B, editors. Images and identities in public administration. London: Sage; 1990. p. 113-31.

6. Block P. Stewardship-choosing service over self-interest. San Francisco: Berrett-Koehler Publishers; 1993.

7. Saltman RB, Ferroussier-Davis O. On the concept of stewardship in health policy. Bull World Health Organ 2000; 78: 732-9.

8. Kumar D, Kapoor N. Learning Lessons for public health from Polio eradication in India. Int J Med Sci Public Health 2014; 3: 384-6. doi: 10.5455/ijmsph.2014.130420141

9. Calman K. Beyond the 'nanny state': stewardship and public health. Public Health 2009; 123: e6-10. doi: 10.1016/j.puhe.2008.10.025

10. Nafees AA, Nayani P. Stewardship in Health Policy and its relevance to Pakistan. Journal of Pakistan Medical Association 2011; 61: 795-800.

11. Enthoven A, Kronick R. A consumer-choice health plan for the 1990s. N Engl J Med 1989; 320: 29-37. doi: 10.1056/nejm198901053200106

12. Boffin N. Stewardship of health systems: Review of the literature [internet]. Antwerp; Institute of Tropical Medicine. 2002. [cited 2014 May 1]. Available from: http://www.itg.be/itg/uploads/publichealth/Review\%20stewardship. pdf

13. Saner M, Wilson J. Stewardship, Good Governance and Ethics [internet]. Institute on Governance. Policy Brief No. 19. December 2003. [cited 2014 May 1]. Available from: http://www.metisportals.ca/cons/wp-content/ uploads/2009/02/stewardship-good-governance-and-ethics.pdf

14. Kaufman D, Kraay A, Zoido-Lobaton P. Aggregating governance indicators. Washington DC: The World Bank; 1999. doi: 10.1596/1813-9450-2195 